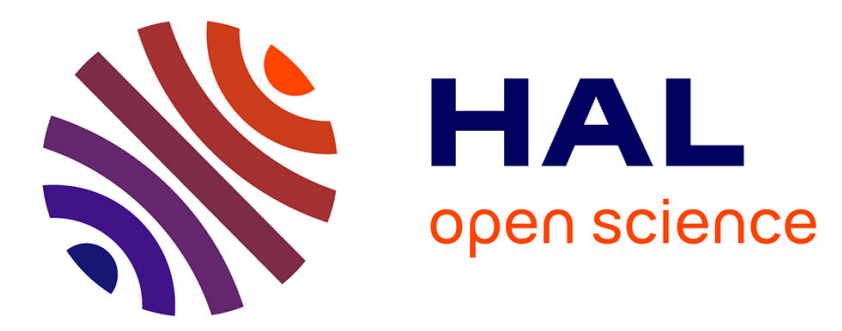

\title{
Accelerated microwave assisted synthesis of alumino-germanate imogolite nanotubes
}

\author{
A. Avellan, C. Levard, Corinne Chaneac, D. Borschneck, Francis R.A. Onofri, \\ Jérôme Rose, A. Masion
}

\section{- To cite this version:}

A. Avellan, C. Levard, Corinne Chaneac, D. Borschneck, Francis R.A. Onofri, et al.. Accelerated microwave assisted synthesis of alumino-germanate imogolite nanotubes. RSC Advances, 2016, 6 (109), pp.108146 - 108150. 10.1039/C6RA19275K . hal-01430836

\section{HAL Id: hal-01430836 \\ https://hal.sorbonne-universite.fr/hal-01430836}

Submitted on 10 Jan 2017

HAL is a multi-disciplinary open access archive for the deposit and dissemination of scientific research documents, whether they are published or not. The documents may come from teaching and research institutions in France or abroad, or from public or private research centers.
L'archive ouverte pluridisciplinaire HAL, est destinée au dépôt et à la diffusion de documents scientifiques de niveau recherche, publiés ou non, émanant des établissements d'enseignement et de recherche français ou étrangers, des laboratoires publics ou privés. 


\title{
Journal Name
}

\section{Accelerated Microwave Assisted Synthesis of Alumino-Germanate Imogolite Nanotubes}

\author{
A. Avellan*a,b, C. Levard ${ }^{a, b}$, C. Chaneac ${ }^{c}$, D. Borschneck ${ }^{a, b}$, Fabrice R.A. Onofrid , J. Rose ${ }^{a, b}$, A. \\ Masion** a,b \\ www.rsc.org/

\begin{abstract}
Ge-imogolite nanotubes $\left(\mathrm{Al}_{2} \mathrm{GeO}_{7} \mathrm{H}_{4}\right)$ can be readily obtained in various lengths, chemical compositions and crystallinities, opening up new perspectives for applications. Their classical synthesis includes the nucleation of roof-tile shaped precursors at room temperature followed by heat promoted growth (typically $95^{\circ} \mathrm{C}$ ) for at least 4 to 7 days. To circumvent this excessively long synthesis duration, we used microwave assisted heating to accelerate the growth. Micron sized tubes were formed from $1 \mathrm{hr}$ at $100^{\circ} \mathrm{C}$, and best results were obtained for 2 hours at $200^{\circ} \mathrm{C}$, i.e approximately 100 fold faster when compared to the conventional heating process. Additionally, tube lengths were shifted towards larger values by one order of magnitude, leading to micron sized Ge-imogolites vs. $100 \mathrm{~nm}$ with conventional heating. Specific microwave effects as well as mechanisms leading to these longer tubes are also discussed.
\end{abstract}

\section{INTRODUCTION}

Tubular nanomaterials are increasingly popular in a number of applications e.g. to improve mechanical strength, pack high surface areas in a limited volume... If carbon nanotubes remain the most publicized materials in this category, much of the focus now shifts towards inorganic nanotubes/nanofibers. Among these, imogolites $\left(\mathrm{Al}_{2} \mathrm{SiO}_{7} \mathrm{H}_{4}\right)$ are nanotubes occurring naturally in volcanic soils, which can be synthesized with simple aqueous sol gel processes. ${ }^{1,2}$ However these protocols have in common very poor yields (millimolar concentrations) and slow kinetics (several days of growth). Yield is no longer an issue, since large quantities of $\mathrm{Ge}$ analogues, isostructural to imogolite $\left(\mathrm{Al}_{2} \mathrm{GeO}_{7} \mathrm{H}_{4}\right.$, hereafter called Ge-imogolites) are readily obtained with initial reagent concentration in the molar range. $^{3}$ The diameter $(3-4.5 \mathrm{~nm})$ is a function of wall multiplicity, which is easily controlled with the initial concentrations. ${ }^{4}$ These hydrophilic tubes can be functionalized on both the internal and external tube surfaces. 5,6

Like silicon-based imogolite, the synthesis of Ge-imogolites is an aqueous phase process where the room-temperature based hydrolysis of a mixture of $\mathrm{Al}$ and $\mathrm{Ge}$ monomers results in the nucleation of roof-tile shaped proto-imogolites (ca. $5 \mathrm{~nm}$ ). Although not entirely elucidated, the mechanisms of tube

a CEREGE, CNRS, Aix-Marseille Université, IRD, UM34, 13545 Aix-en-Provence, France.

b iCeint - International Center for the Environnemental Implications of NanoTechnologies, Europôle de l'Arbois, 13545 Aix-en-Provence, France.

c Chimie de la Matière Condensée de Paris - UMR7574 (UPMC/CNRS); Collège de France; 11, place Marcelin Berthelot; 75231 Paris; France

${ }^{d}$ IUSTI, CNRS, Aix-Marseille Université, UMR 7343, 13453, Marseille, France

Electronic Supplementary Information (ESI) available: [Figure S1 Repartition in volume percentage of Ge-imogolites nanotube lengths estimated from AFM images. Figure S2 Method for height thresholding used to distinguish protoimogolites from tubes are presented]. See DOI: 10.1039/x0xx00000x growth, during a growth step at moderate temperature for several days, are thought to include the formation of annular structure from proto-imogolite upon heating, followed by tube growth via tip-to-tip collisions. ${ }^{7}$ Under these conditions, average tube length is a few tens of nanometers with a maximum length typically not exceeding $150 \mathrm{~nm}$. Some microsized Ge-imogolites were obtained using urea instead of $\mathrm{NaOH}$ during hydrolysis. ${ }^{8}$ However the growth still requires a week, and it is unclear to what extent the formation of long tubes is a quantitative process.

Predominantly short tubes $(<200 \mathrm{~nm})$ and long growth duration are detrimental characteristics of all the Ge-imogolite syntheses available in the literature. To overcome these limitations, at least partly, we investigated the improvements that microwave (MW) heating could offer in comparison to conventional heating in an oven. $\mathrm{MW}$ is widely used for the synthesis of organic materials and, to a lesser extent, for the synthesis of minerals. Using conventional heating $(\mathrm{CH})$, thermal energy is delivered to the material surface by radiant and/or convection heating and is transferred to the bulk solution via conduction. During MW processing, polar water molecules tend to align with the changing alternating electric field, and energy is transferred by rotation, friction and collision. As a result, heat can be generated homogenously throughout the volume. ${ }^{9}$ In the literature, MW synthesis have increased reaction rates, improved yield and narrowed nanoparticle size distribution. ${ }^{10-14}$ These improvements cannot be explained solely by a rapid heating effect, and therefore various authors postulate the existence of a "specific microwave effect". ${ }^{15}$ In the present study, we report the effects of MW heating on the formation of Ge-imogolite as a function of reaction time and temperature. 


\section{METHODS}

Ge-imogolite precursors (proto-imogolites) were obtained by adding a germanium ethoxide solution to aluminum chloride (0.05 mol.L-1, $\left.\mathrm{n}_{\mathrm{Al}} / \mathrm{n}_{\mathrm{Ge}}=1.75\right)$. The solution was slowly hydrolyzed with a $0.05 \mathrm{~mol} . \mathrm{L}^{-1} \mathrm{NaOH}$ solution $(1 \mathrm{ml} / \mathrm{min})$ to a hydrolysis ratio $\left(\mathrm{R}=\mathrm{n}_{\mathrm{OH}} / \mathrm{n}_{\mathrm{Al}}\right)$ of 2 . Proto-imogolites were refrigerated at $4^{\circ} \mathrm{C}$ before further use. Tubes growth was performed either under Conventional Heating $(\mathrm{CH})$ in an oven with pressure resistant containers or under microwave (MW) irradiation (Anton Paar Synthos 3000 microwave, $2.45 \mathrm{GHz}$ ) under stirring. For both heating regimes, 3 temperatures (100, 150 and $200^{\circ} \mathrm{C}$ ) and 2 durations $(1 \mathrm{~h}$ and $2 \mathrm{~h}$ ) were tested; $\mathrm{CH}$ systems were also heated for 7 days, the $\mathrm{CH}$ system at $100^{\circ} \mathrm{C}$ during 7 days being a reference of current protocols. The final suspensions were dialyzed with a $1 \mathrm{kDa}$ pore size membrane against ultra pure water until the conductivity reached 2 $\mu \mathrm{S} . \mathrm{cm}^{-1}$. AFM images (Bruker INOVA) were obtained in tapping mode. Diluted samples (1mg. $\left.\mathrm{L}^{-1}\right)$ were deposited on a mica sheet and dried several hours at $60^{\circ} \mathrm{C}$ prior to analysis. AFM images extraction and height profile thresholds were performed using Gwyddion 2.4 software. ${ }^{16}$ Particle counting, length and height distributions were extracted using Fiji 2.0 plugin $^{17}$ and image J 1.46 software. ${ }^{18}$ As opposed to height resolution $(0.2 \mathrm{~nm})$, lateral resolution was poor and limited to $25 \mathrm{~nm}$ by the dimensions of the AFM tip; therefore protoimogolites were determined on the basis of their height (ca. $1 \mathrm{~nm}$, vs. 3.5 for the tubes) and not their length which is indistinguishable from the shortest tubes. To this end, a threshold of $2.5 \mathrm{~nm}$ was applied using the Gwyddion software (cf. Fig. S2 in S.I. for details). X-ray diffraction patterns were obtained on freeze-dried dialyzed samples using an X'Pert Pro diffractometer (PANalytical) equipped with a rotating glass capillary $(\varnothing 300 \mu \mathrm{m})$ and a mirror as a primary optics to

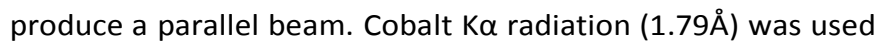
at $40 \mathrm{kV}$ and $40 \mathrm{~mA}$. Scans were performed in the scattering angle range $2 \theta=2-55^{\circ}$ with steps of $0.05^{\circ}$ and 15 s per step.

\section{RESULTS AND DISCUSSION}

The reference sample, i.e. 7 days $\mathrm{CH}$ at $100^{\circ} \mathrm{C}$, corresponds to the most common protocol described in the literature. The $\mathrm{X}$ ray diffraction patterns of the recovered tubes of this
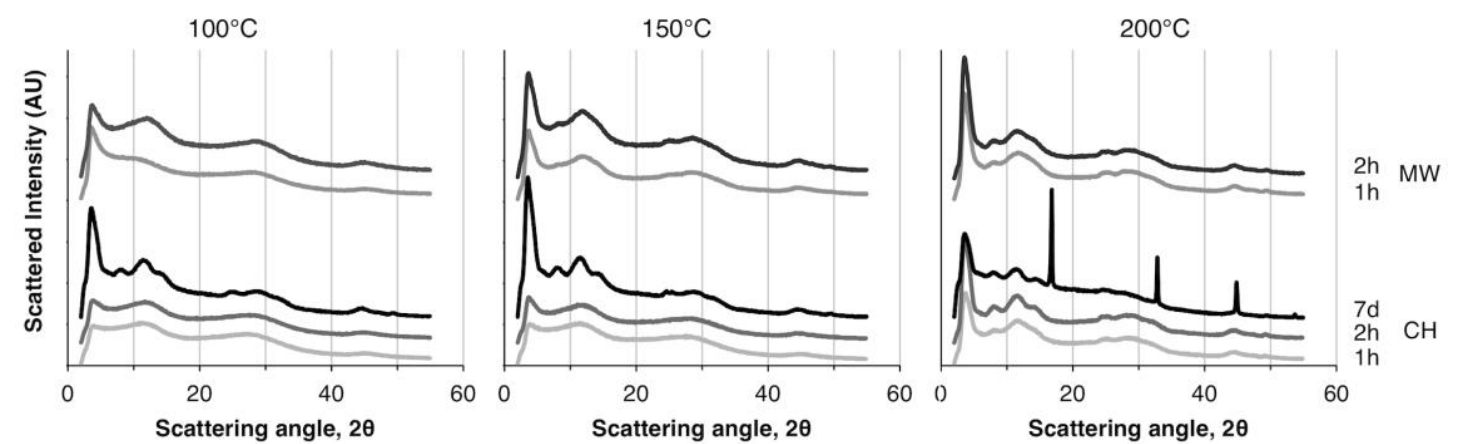

reference sample (Figure 1) corresponds to the pattern previously observed with Ge-imogolites.6,19 As expected, average tube length as determined by Atomic Force Microscopy (AFM) is below $80 \mathrm{~nm}$ (Figure 2) and the maximum does not exceed $150 \mathrm{~nm}$ (Figure 3(a)). Increasing the temperature to $150^{\circ} \mathrm{C}$ and $200^{\circ} \mathrm{C}$ resulted in poorer results. While the diffraction patterns still display the signature of Geimogolite (Fig. 1), only very few tubes were detected by AFM (Fig. 2). Instead, the AFM images are dominated by globular structures, presumably aggregates of precursors and/or illordered aluminum (oxy)hydroxides at $150^{\circ} \mathrm{C}$, and an additional boehmite contribution (AIOOH; ICDD PDF \#74-1895) (Fig.1) at $200^{\circ} \mathrm{C}$, possibly resulting from the maturation of the species formed at $150^{\circ} \mathrm{C}$.

Figure 4 shows the proportions of proto-imogolite (i.e height $<1 \mathrm{~nm}$ ), short tubes (i.e. length $<25 \mathrm{~nm}$ ) and "long" tubes (i.e. length $>25 \mathrm{~nm}$ ) as determined from AFM images analysis. Under $\mathrm{CH}$ conditions, no tubes are present at $100^{\circ} \mathrm{C}$ after 1 and 2 hours heating. Above $100^{\circ} \mathrm{C}$, the proportion of tubes formed under $\mathrm{CH}$ conditions increases with the reaction temperature and reaction time to reach $90 \%$ at $200^{\circ} \mathrm{C}$ after 2 hours, short tubes $(<25 \mathrm{~nm})$ being the predominant structure. The X-ray diffraction patterns are consistent with Ge-imogolite formation. ${ }^{19}$ (Fig. 1) To the best of our knowledge, this is the first report unequivocally documenting the early formation of Ge-imogolite (i.e. within one or two hours) under hydrothermal conditions. However, it appears that the formed Ge-imogolite cannot withstand prolonged maturation under these conditions since they become undetectable on the AFM images after 7 days (Fig. 2).

Synthesis results obtained with $\mathrm{MW}$ contrast sharply their $\mathrm{CH}$ counterpart. The most striking result is that micron-sized tubes are detected at the lowest temperature and shortest time $\left(100^{\circ} \mathrm{C}, 1 \mathrm{~h}\right)$ (Fig. 2). At this stage, there is still a majority of proto-imogolite present in the sample. Increasing the temperature and duration causes this proportion to gradually decrease, mainly to the benefit of long ( $>25 \mathrm{~nm}$ ) tubes, which are the only detected structures after $2 \mathrm{~h}$ at $200^{\circ} \mathrm{C}$ (Figs. 3 and 4).

\footnotetext{
Figure 1: X-ray diffraction patterns of samples grown at 100,150 or $200^{\circ} \mathrm{C}$ under conventional heating $(\mathrm{CH})$ or microwave (MW) irradiation for $1 \mathrm{~h}, 2 \mathrm{~h}$ or 7 days.
} 


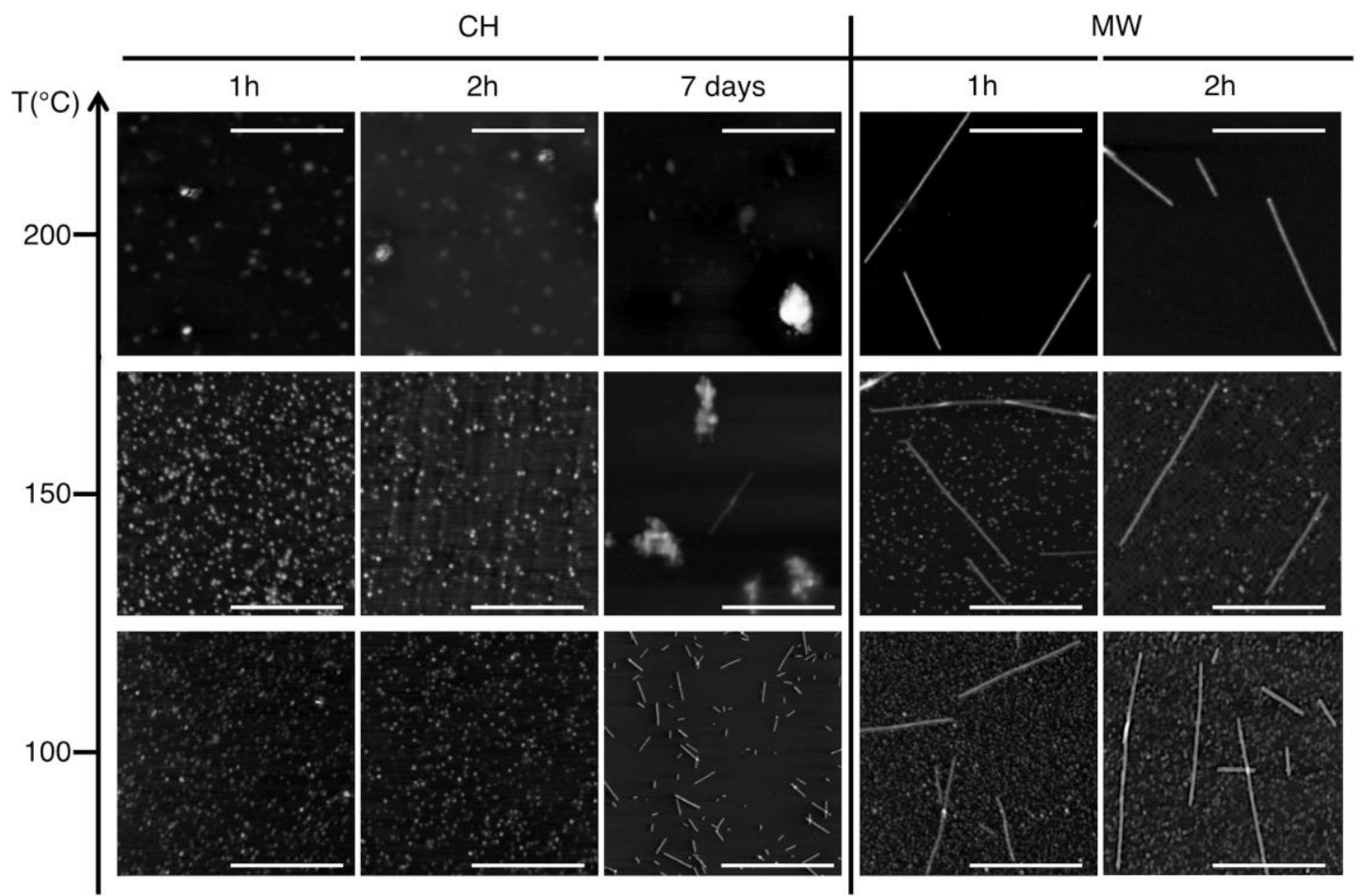

Figure 2: AFM images under tapping mode for samples synthesized under conventional heating $(\mathrm{CH})$ or microwave $(\mathrm{MW})$ irradiation, at 100,150 or $200^{\circ} \mathrm{C}$. Scale bar $=500 \mathrm{~nm}$. Grey level is related to the height of the particles.

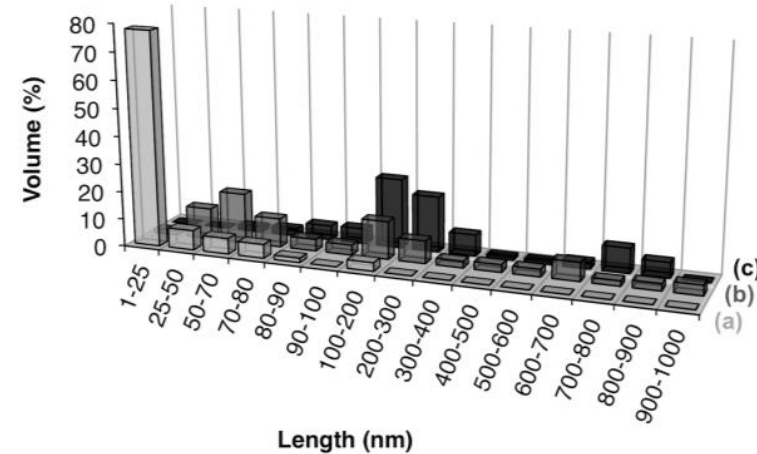

Figure 3: Repartition in volume percentage of the length of Ge-imogolites nanotube measured from AFM images. At least 500 particles were considered excluding aggregates. Growth stages were performed under (a) conventional heating at $100^{\circ} \mathrm{C}$ for 7 days or under microwave irradiation at $200^{\circ} \mathrm{C}$ (b) $1 \mathrm{~h}$ or (c) $2 \mathrm{~h}$.

Using $\mathrm{MW}$, the reaction rate is accelerated by a factor close to 100 compared to $\mathrm{CH}$ protocols. This is accompanied by a shift in the tube length by approximately one order of magnitude (Fig. 3). To the best of our knowledge, there is no previous evidence of the synthesis of micron-sized Ge-imogolite in such a short time frame.

Micron-sized Ge-imogolite was also obtained previously using urea as hydrolysis agent with considerably slower kinetics than the present study, i.e. 5 days of heating. ${ }^{8}$. The maximum lengths measured under these conditions were around $1 \mu \mathrm{m}$, which is also the case with our MW based protocol. This length might correspond to an "equilibrium" value since two different growth procedures lead to the same maximum value he systems hydrolyzed with urea was described as very polydispersed in length. ${ }^{8}$ In the present case, the particle size distribution can be termed as bimodal with maxima around 300 and $800 \mathrm{~nm}$ (Fig. 3 and Fig. S1 in Supporting Information (S.I.)), and may be an improvement in term of length selectivity compared to the urea based protocol. However, a particle size distribution of the solids formed following this procedure is required to confirm this hypothesis

Amara et al. hypothesize an urea mediated modification of the interactions between the tips of the tubes to explain the increased length, but did not give further details on the nature of the mechanisms involved. ${ }^{8}$ The present results are consistent with a structuring role of urea during tube formation. Indeed, when the growth is conducted under similar conditions (viz. $\mathrm{CH}, 150^{\circ} \mathrm{C}$ for 7 days vs. $140^{\circ} \mathrm{C}$ for 5 days for the urea based protocol), only negligible amounts of tubes are produced from $\mathrm{NaOH}$ hydrolyzed systems (Fig. 2), thereby suggesting that urea and/or its decomposition by-products not only promote tube lengthening, but also prevent the decomposition/destructuration of the short tubes formed in the initial stages of heating. In the present study, it is obvious that the enhanced tube growth under MW heating is the result of a different mechanism. 


\section{Journal Name}

\section{ARTICLE}

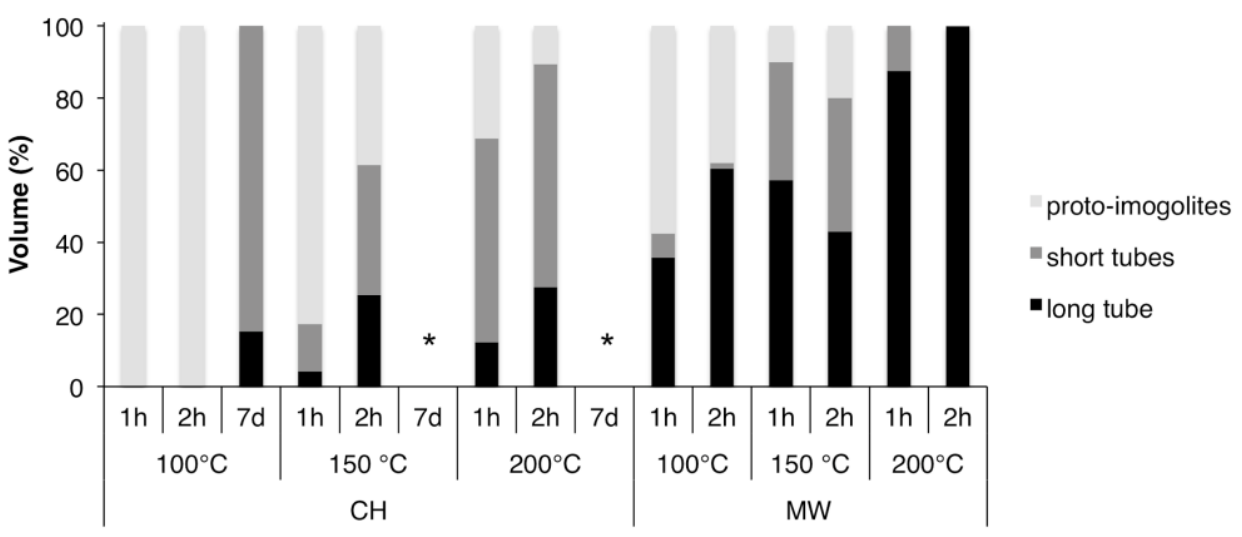

Figure 4: Repartition in volume percentage and type: proto-imogolites, short tubes (length $<25 \mathrm{~nm}$ ) or long tubes (length $>25 \mathrm{~nm}$ ) measured from AFM images, for various temperatures, growing durations and the two heating conditions. CH: Conventional Heating, MW: MicroWave irradiation *: samples dominated by large aggregates preventing the determination of tube proportions.

The MW induced molecular motion of polar species causes homogenous heating throughout the sample volume, ${ }^{20}$ but increased molecular mobility is not necessarily linked to thermal effects. ${ }^{21}$ The fast and homogeneous increase in temperature under MW irradiation certainly increases the kinetics of tube formation. However this faster molecular motion is not sufficient to explain the observed enhancement of the tube length. As a matter of fact, it appears that prolonged heating at temperature above $100^{\circ} \mathrm{C}$ has even adverse effects on tube growth as shown by the quasi-absence of Ge-imogolites for the systems that underwent $\mathrm{CH}$ at 150 and $200^{\circ} \mathrm{C}$ during 7 days (Fig.2). Interestingly, this temperature dependent destructuring of short Ge-imogolite tubes is not observed when $\mathrm{MW}$ are applied, and increasing proportions of long tubes are formed instead (Figs. 2 and 4).

Improvement of the tube growth could be achieved by favoring tip-to-tip collisions, since this has been hypothesized as major growth mechanism. ${ }^{7}$ The most obvious way to accomplish this, is to restrict, at least partly, the randomness in particle collisions, i.e. promoting the alignment of the tubes within the sample, which equates to eliminating 2 degrees of liberty and thus a theoretical increase of the probability of effective collisions by 4 to 5 orders of magnitude depending on symmetry.

In this context, a specific MW effect could be the alignment of imogolites tubes along the MW electric field streamlines. Recent experiments, carried out with polarized light extinction spectroscopy, ${ }^{22,23}$ have clearly demonstrated that in the 0.3-6 $\mathrm{MHz}$ range, where the electrical properties of water are expected to be comparable to the $\mathrm{GHz}$ range, electric field gradients of $50 \mathrm{~V} / \mathrm{mm}$ are sufficient to align aqueous suspensions of imogolites nanotubes of a few tens of nanometers. On the other hand, for such moderate electric field gradients, electromagnetic calculations show that the induced dielectric force and dielectric moment are directly proportional to the particle electrical polarisability and thus, to the square of their length in the case of elongated particles such as nanotubes. As a consequence, the effect of the dielectric force induced by $\mathrm{MW}$ increases quadratically with the length of nanotubes, limiting their rotation induced by the Brownian motion and thus, to some extent, thermal effects. It is believed that such a mechanism would be most effective in promoting the tip-to-tip collisions between long tubes (and thus rare at the beginning of the process), leading to the formation of micrometer-long tubes rather than nanometer of a few tens nanometers long.

For the $\mathrm{MW}$ systems at $100^{\circ} \mathrm{C}$, proto-imogolite and long tubes are the major species while the proportion of short tubes is surprisingly low. This suggests an additional growth mechanism, according to which tubes grow from the addition of proto-imogolite. Since Ge is a good MW absorber (i.e. high equivalent electrical permittivity), ${ }^{24}$ hotspots are likely to occur where $\mathrm{Ge}$ atoms are concentrated, i.e. the tubes and precursors, thus creating a favorable environment from an energy standpoint.

Obviously, these two mechanisms probably take place simultaneously. They are also not fully inconsistent since, for instance, the forced orientation of the largest nanotubes should also promote the assembly at their tips of protoimogolites (which are probably less sensitive to the MW electrical field).

\section{Conclusions}


The use of MW is a significant step forward in the synthesis of Ge-imogolite (100 times faster and tubes 10 times longer than with $\mathrm{CH}$ ), and could be the key to commercial applications of this material. A better control over the tube length might be required to tailor tubes to specific uses. This means a more indepth investigation of the mechanisms involved, their relative importance during the entire process. Here, it would be a matter of determining at which stage precursor addition or tube-tube collision are the predominant mechanism. To do so, monitoring particle orientation during the entire process is an essential piece of information. This aspect, which is far from being straightforward, is currently under investigation.

\section{Acknowledgements}

We acknowledge support from the French National Research Agency (no. ANR-11-NANO-008-04; ANR-11-NANO-008-06). This work is also a contribution to the Labex Serenade (ANR11-LABX-0064) funded by the "Investissements d'Avenir» French Government program of the French National Research Agency (ANR) through the A*MIDEX project (ANR-11-IDEX0001-02).

\section{Notes and references}

1 V. C. Farmer, A. R. Fraser and J. M. Tait, J. Chem. Soc. Chem. Commun., 1977, 462-463.

2 M. Suzuki and K. Inukai, in Inorganic and Metallic Nanotubular Materials, ed. T. Kijima, Springer Berlin / Heidelberg, 2010, vol. 117, pp. 159-167.

3 C. Levard, J. Rose, A. Masion, E. Doelsch, D. Borschneck, L. Olivi, C. Dominici, O. Grauby, J. C. Woicik and J.-Y. Bottero, J. Am. Chem. Soc., 2008, 130, 5862-5863.

4 A. Thill, P. Maillet, B. Guiose, O. Spalla, L. Belloni, P. Chaurand, M. Auffan, L. Olivi and J. Rose, J. Am. Chem. Soc. 2012, 134, 3780-3786.

5 C. Zanzottera, A. Vicente, E. Celasco, C. Fernandez, E. Garrone and B. Bonelli, J. Phys. Chem. C, 2012, 116, 7499-7506.

6 A. Avellan, C. Levard, N. Kumar, J. Rose, L. Olivi, A. Thill, P. Chaurand, D. Borschneck and A. Masion, RSC Adv., 2014, 4, 49827-49830.

7 P. Maillet, C. Levard, O. Spalla, A. Masion, J. Rose and A. Thill, Phys. Chem. Chem. Phys. PCCP, 2011, 13, 2682-2689.

8 M.-S. Amara, E. Paineau, M. Bacia-Verloop, M.-E. M. Krapf, P. Davidson, L. Belloni, C. Levard, J. Rose, P. Launois and A. Thill, Chem. Commun., 2013, 49, 11284-11286.

9 S. Das, A. K. Mukhopadhyay, S. Datta and D. Basu, Bull. Mater. Sci., 2009, 32, 1-13.

10 Y. Li, E. J. Lee and S. O. Cho, J. Phys. Chem. C, 2007, 111 14813-14817.

11 J. Miyawaki, M. Yudasaka, H. Imai, H. Yorimitsu, H. Isobe, E. Nakamura and S. lijima, Adv. Mater., 2006, 18, 1010-1014.

12 L. Vovchenko, L. Matzui, M. Zakharenko, M. Babich and A. Brusilovetz, J. Phys. Chem. Solids, 2004, 65, 171-175.

13 Y.-J. Zhu and F. Chen, Chem. Rev., 2014, 114, 6462-6555.

14 J. A. Gerbec, D. Magana, A. Washington and G. F. Strouse, J. Am. Chem. Soc., 2005, 127, 15791-15800.

15 S. C. Motshekga, S. K. Pillai, S. Sinha Ray, K. Jalama and R. W. M. Krause, J. Nanomater., 2012, 2012, e691503.

16 D. Nečas and P. Klapetek, Cent. Eur. J. Phys., 2011, 10, 181188.
17 J. Schindelin, I. Arganda-Carreras, E. Frise, V. Kaynig, M. Longair, T. Pietzsch, S. Preibisch, C. Rueden, S. Saalfeld, B. Schmid, J.-Y. Tinevez, D. J. White, V. Hartenstein, K. Eliceiri, P. Tomancak and A. Cardona, Nat. Methods, 2012, 9, 676-682.

18 C. A. Schneider, W. S. Rasband and K. W. Eliceiri, Nat. Methods, 2012, 9, 671-675.

19 M. Bizi, J. Porous Mater., 2015, 22, 1589-1597.

20 I. Bilecka and M. Niederberger, Nanoscale, 2010, 2, 13581374 .

21 A. de la Hoz, Á. Díaz-Ortiz and A. Moreno, Chem. Soc. Rev., 2005, 34, 164-178.

22 F. R. A. Onofri, S. Barbosa, O. Touré, M. Woźniak and C. Grisolia, J. Quant. Spectrosc. Radiat. Transf., 2013, 126, 160-168. 23 E. Paineau, M.-E. M. Krapf, M.-S. Amara, N. V. Matskova, I. Dozov, S. Rouzière, A. Thill, P. Launois and P. Davidson, Nat. Commun., 2016, 7, 10271.

24 E. Muthuswamy, A. S. Iskandar, M. M. Amador and S. M. Kauzlarich, Chem. Mater., 2013, 25, 1416-1422. 